\title{
VAI TRÒ CỦA NỘI SOI TRUNG THÂTT TÙ’ ĐƯờNG CỔ TRONG CHẨN ĐOÁN BẢN CHẤT CÁC KHỐI U VÀ HẠCH VÙNG TRUNG THẤT
}

\author{
Ngô Quốc Hung *, Vũ Hũu Vĩnh *, Lê Nũ Hoà Hiệp**
}

\section{TÓM TẮT}

Từ 9/2010 đến $2 / 2015$, chúng tôi ghi nhận 81 trường hợp được nội soi trung thất từ đường cổ làm chẩn đoán. Tỉ lệ Nam: Nữ $=2,5$ độ tuổi trung bình $41.1 \pm 17,6$. Trong đó , 46 ca là u trung thất, 20 ca là hạch trung thất trên bệnh nhân u phổi và 15 ca hạch trung thất đơn thuần. Chúng tôi ghi nhận độ nhạy của nội soi trung thất là $98,7 \%$, độ đặc hiệu $100 \%$, giá trị tiên đoán âm $66,8 \%$, độ chính xác $97,5 \%$. Tỉ lệ thất bại trong nội soi trung thất là $3,7 \%$ có 1 trường hợp biến chứng và không có trường hợp nào tử vong. Nội soi trung thất từ đường cổ có giá trị chẩn đoán cao, độ nhạy và độ đặc hiệu trên $95 \%$, an toàn và ít có biến chứng.

\section{ROLE OF CERVICAL}

\section{MEDIASTINOSCOPY IN THE DIAGNOSIS}

OF THE MASS OR LYMPHOM MEDIASTINAL

In over 4 years, we collected 81 patients. The gender ratio Male : female was 2,5, mean age was $41.1 \pm 17,6$ In that, 46 cases were mediastinal tumor, 20cases were lymphom mediastinal in the lung tumor and 16 cases were unknown lymphom mediastinal. We found the sensitive was $98,7 \%$ the specitive was $100 \%$, the predict negative was $66,8 \%$, the accuracy was $97,5 \%$ The fail of cervical mediastinoscopy was $3,7 \%$ we have 1 case of complication and no have case of death. Cervical mediastinoscopy have the sensitive, the specitive over $95 \%$ in the diagnosis of the mass and lymphom mediastinal. This method was save and low of complication.
Key word: Cervical mediastinoscopy, mediastinal tumor, lymphoma mediastinal.

\section{I. ĐặT VẤN ĐỀ:}

Nội soi trung thất (NSTT) được áp dụng lần đầu tiên trong lâm sàng vào năm 1959 do Carlens thực hiện[4]. Từ đó đến nay, nội soi trung thất đã có những bước phát triển vượt bậc và được xem là "tiêu chuẩn vàng" trong chẩn đoán bản chất các u, hạch vùng trung thất [3],[4]. Nội soi trung thất sinh thiết được chỉ định chủ yếu cho đánh giá giai đoạn ung thư phổi qua sinh thiết tìm bản chất của hạch trung thất. Ngoài ra, NSTT còn được chỉ định cho việc đánh giá lại giai đoạn ung thư phổi sau khi bệnh nhân hoá trị, đánh giá bản chất các khối u vùng trung thất giữa và điều trị các u nang vùng trung thất [4], [11]. NSTT còn được chỉ định trong các trường hợp hạch trung thất giữa chưa rõ nguyên nhân[4], []].

Theo các tác giả trên thế giới, NSTT có tỉ lệ thất bại rất thấp, khoảng $5 \%[\underline{5}]$, []]. Các biến chứng có thể xảy ra như tràn khí màng phổi, tổn thương dây thần kinh quặt ngược, chảy máu khi sinh thiết và tổn thương các mạch máu lớn trong trung thất. Tuy vậy, tỉ lệ biến chứng và tỉ lệ tử vong trong NSTT rất thấp dưới 1\%[9]. Với các hiểu biết trên, chúng tôi tiến hành nghiên cứu vai trò của NSTT trong việc chẩn đoán bản chẩn chất các khối $\mathrm{u}$, hạch vùng trung thất và

* Khoa ngoại lồng ngục bệnh viện Chợ Rẫy

** Đại hoc Y Duoọc TP. Hồ Chí Minh Ngườ chịu trách nhiệm khoa học: PGS.TS. Lê Nũ Hoà Hiệp Ngày nhận bài: 10/02/2017- Ngày Cho Phép Đăng: 10/03/2017 Phản Biện Khoa học: PGS.TS. Đặng Ngọc Hùng GS.TS. Bùi Đúc Phú 
bước đầu áp dụng trên lâm sàng tại Bệnh viện Chợ Rẫy.

\section{II. ĐỐI TƯợNG VÀ PHƯƠNG PHÁP NGHIÊN CỨU:}

Chúng tôi tiến hành nghiên cứu hồi cứu mô tả cắt ngang. Tất cả các bệnh nhân nhập viện Chợ Rẫy tại Khoa Ngoại lồng ngực có các khôi $\mathrm{u}$, hạch vùng trung thất chưa có giải phẫu bệnh, được chỉ định NSTT đường cổ để tìm chẩn đoán từ $9 / 2010$ đến $2 / 2015$. Chúng tôi thu nhận được 81 bệnh nhân.

Bệnh nhân được phân thành 3 nhóm bệnh lý với các chỉ định NSTT như sau:

Nhóm 1: Bệnh nhân được chẩn đoán $\mathrm{u}$ trung thất.

- Bệnh nhân có hình ảnh CT scan u trung thất trước hay trung thất giữa, kích thước lớn, có hay không có các tình trạng: chèn ép mạch máu hay khí quản, xâm lấn mạch máu hay khí quản.

- Đối với các u trung thất sau chúng tôi không nhận vào mẫu nghiên cứu vì không tiếp cận $\mathrm{u}$ được bằng đường nội soi trung thất từ cổ.

- Bệnh nhân có u trung thất kèm hạch vùng cổ hay vùng khác, đã sinh thiết nhưng vẫn chưa có kết luận chẩn đoán chúng tôi mới chỉ định nội soi trung thất đường cổ để sinh thiết trực tiếp $\mathrm{u}$.

Nhóm 2: Bệnh nhân được chẩn đoán u phổi có hạch trung thất:

- Bệnh nhân được chẩn đoán u phổi qua hình ảnh CT scan có khối u ở phổi bất kể vị trí và kích thước.

- Bệnh nhân có khối u phổi nguyên phát hay thứ phát sau 1 bệnh lý ung thư chỗ khác đều được thu nhận vào nghiên cứu

- Bệnh nhân đã có chẩn đoán ung thư phổi thông qua: sinh thiết xuyên kim qua thành ngực, nội soi phế quản nhưng có hạch trung thất lớn hơn $1 \mathrm{~cm}$ trên hình ảnh $\mathrm{CT}$ scan ngực, có chỉ định sinh thiết hạch trung thất chẩn đoán giai đoạn ung thư phổi đều được vào nhóm nghiên cứu.

- Bệnh nhân có hạch cổ đã được sinh thiết ra kết quả ung thu phổi di căn hạch cổ thì không có chỉ định sinh thiết hạch trung thất làm chẩn đoán.

Nhóm 3: Bệnh nhân được chẩn đoán có hạch trung thất đơn thuần.

- Bệnh nhân được chẩn đoán có hạch trung thất trên CT scan khi hạch trung thất lớn hơn 1 $\mathrm{cm}$ và có nhiều hơn 2 hạch.

- Bệnh nhân có thể có các hạch vùng khác đi kèm theo. Bệnh nhân có thể đã được sinh thiết hạch các vùng khác làm chẩn đoán nhưng chưa có kết quả giải phẫu bệnh.

Tất cả bệnh nhân được NSTT từ đường cổ theo quy chuẩn để sinh thiết các $\mathrm{u}$, hạch trung thất . Bệnh nhân được ghi nhận tất các các yếu tố lâm sàng, hình ảnh $\mathrm{CT}$ scan ngực có cản quang, các yếu tố trong phẫu thuật như : kích thước rạch da, thời gian phẫu thuật, số lượng máu mất, vị trí sinh thiết, số mẫu sinh thiết, kích thước mẫu sinh thiết... Ghi nhận các biến chứng, tỉ lệ thất bại, thời gian nằm viện và đánh gía kết quả phẫu thuật như sau:

- Tốt: Bệnh nhân sinh thiết an toàn, được xuất viện và không có biến chứng nào.

- Trung bình: bệnh nhân sinh thiết an toàn, được xuất viện nhưng có biến chứng nhẹ như tụ máu hay dịch vết mổ, tràn khí tràn máu cần phải đặt dẫn lưu màng phổi điều trị, khàn giọng, nhiễm trùng vết mổ.

- Xấu : bệnh nhân có các biến chứng nặng như chảy máu nhiều từ các động mạch lớn, thủng thực quản, thủng khí quản cần mở ngực hay mở xương ức xử lý tổn thương.

- Thất bại: Bệnh nhân sinh thiết an toàn nhưng kết quả giải phẫu bệnh không chẩn đoán được bệnh : mô viêm xơ mạn, mô mỡ, mô liên kết... 
Tất cả các dữ liệu sẽ được ghi nhận và xử lý square, t- test two-side được sử dụng và tính ra độ với phần mềm SPSS 20.0. Các test thống kê chi- nhạy, độ đặc hiệu, giá trị tiên đoán âm của NSTT.

\section{KẾT QUẢ:}

Qua hơn 4 năm nghiên cứu, chúng tôi ghi nhận 81 trường hợp bệnh nhân nhập viện Khoa Ngoại Lồng ngực và được sinh thiết chẩn đoán qua NSTT đường cổ với các kết quả như sau:

Bảng 3.1: Đặc điểm lâm sàng nhóm nghiên cưu :

\begin{tabular}{|c|c|c|c|c|}
\hline & $\begin{array}{l}\text { U trung thất } \\
(\mathrm{n}=46)\end{array}$ & $\begin{array}{l}\text { Hạch trung thất/ } \\
\text { U phổi } \\
(n=20)\end{array}$ & $\begin{array}{l}\text { Hạch trung } \\
\text { thất đơn } \\
\text { thuần }(\mathrm{n}=15)\end{array}$ & $\mathrm{P}$ value \\
\hline Giới tính & & & & $0,47 *$ \\
\hline Nam & 33 & 14 & 13 & \\
\hline Nũ & 13 & 6 & 2 & \\
\hline Tuổi trung bình & $41.1 \pm 17,6$ & $45,7 \pm 9,7$ & $47,7 \pm 12,8$ & $0.16^{* *}$ \\
\hline \multicolumn{5}{|l|}{ Lý do nhập viện } \\
\hline Đau ngực & 13 & 5 & 4 & $0,45^{*}$ \\
\hline Tình cờ & 4 & 5 & 2 & \\
\hline Ho khan & 13 & 4 & 4 & \\
\hline Hội chứng chèn ép TM chủ trên & 35 & 1 & 2 & $0,001 *$ \\
\hline Tiền căn ung thư & 1 & 4 & - & $0,85^{*}$ \\
\hline
\end{tabular}

Bảng 3.2: Đặc điểm phẫu thuật và kết quả phẫu thuật của nhóm nghiên cứu:

\begin{tabular}{|c|c|c|c|c|}
\hline & $\begin{array}{l}\text { U trung thất } \\
(\mathrm{n}=46)\end{array}$ & $\begin{array}{l}\text { Hạch trung thất/ } \\
\text { U phổi } \\
(\mathrm{n}=20)\end{array}$ & $\begin{array}{l}\text { Hạch trung thất } \\
\text { đơn thuần } \\
(\mathrm{n}=15)\end{array}$ & $\mathrm{P}$ value \\
\hline \multicolumn{5}{|l|}{ Vị trí sinh thiết } \\
\hline Cạnh phải KQ & 42 & 7 & 4 & $0,001 *$ \\
\hline Cạnh trái KQ & 3 & 12 & 9 & \\
\hline Dưới carina & 1 & 1 & 2 & \\
\hline Thò̀i gian phẫu thuật (phút) & $68,9 \pm 21,2$ & $78,5 \pm 14,2$ & $78,9 \pm 24,5$ & $0,13 * *$ \\
\hline Lượng máu mất (ml) & $39,5 \pm 11,5$ & $33,3 \pm 8,4$ & $34,5 \pm 10,3$ & $0,09 * *$ \\
\hline \multicolumn{5}{|l|}{ Kết quả phẫu thuật } \\
\hline Tốt & 43 & 20 & 14 & $0,001^{*}$ \\
\hline Trung bình & - & - & - & \\
\hline Xấu & 1 & - & - & \\
\hline Thất bại & 2 & - & 1 & \\
\hline
\end{tabular}


Bảng 3.3: Độ nhạy, độ đặc hiệu và giá trị tiến đoán âm của nghiên cứu:

\begin{tabular}{lcc}
\hline & $\begin{array}{c}\text { U trung thất } \\
(\mathrm{n}=46)\end{array}$ & $\begin{array}{c}\text { Nội soi trung thất } \\
(\mathrm{n}=81)\end{array}$ \\
\hline Độ nhạy & $97,8 \%$ & $98,7 \%$ \\
Độ đặc hiệu & $100 \%$ & $100 \%$ \\
Gía trị tiên đoán âm & $50 \%$ & $66,8 \%$ \\
Độ chính xác & $95,8 \%$ & $97,5 \%$ \\
\hline
\end{tabular}

\section{BÀNLUẬn:}

Trong nghiên cứu của chúng tôi, thu nhận được 81 các trường hợp bệnh nhân được NSTT. Trong đó, tỉ lệ nam nữ là 2,5 , độ tuổi trung bình thường gặp là $41.1 \pm 17,6$. Chúng tôi phân loại thành 3 nhóm và không tìm thấy sự khác biệt có ý nghĩa thống kê giữa độ tuổi trung bình và 3 nhóm nghiên cứu. Về đặc điểm nhập viện của nhóm nghiên cứu chúng tôi ghi nhận được tình trạng phát hiện tình cờ chiến $13,5 \%$. Điều này cho thấy các bệnh lý $u$, hạch vùng trung thất thường có các triệu chứng nghèo nàn khiến bệnh nhân thường nhập viện ở giai đoạn muộn. Kết quả này cũng tương tự với tác giả Huỳnh Quang Khánh[1]và Trương Thanh Thiết[2].

Ghi nhận trên lâm sàng có 38 trường hợp biểu hiện hội chứng chèn ép tĩnh mạch chủ(TMC) trên . Biểu hiện chèn ép gặp chủ yếu ở nhóm u trung thất so với các nhóm còn lại, điều này có ý nghĩa thống kê $(p=0,001)$. Khi bệnh nhân có hội chứng chèn ép tĩnh mạch chủ trên trên lâm sàng sẽ gây ra tình trạng ứ trệ hệ thống mao mạch và các mô xung quanh vùng khí quản điều này gây ra tình trạng dễ chảy máu trong khi sinh thiết.

Tác giả Theodosios Dosios[10]nghiên cứu đoàn hệ hồi cứu các bệnh nhân được NSTT sinh thiết, tác giả so sánh trên 39 trường hợp có chèn ép TMC trên với 367 bệnh nhân không có biểu hiện chèn ép TMC trên được NSTT sinh thiết ghi nhận kết quả: Ở nhóm bệnh nhân có chèn ép TMC trên, tỉ lệ biến chứng là $15,4 \%$, trong đó biến chứng thường gặp là chảy máu chiếm $33,3 \%$, kế đến là biến chứng tắc nghẽn khí quản chiếm 33,3\%. Còn ở nhóm bệnh nhân không có tình trạng chèn ép TCM trên, tác giả ghi nhận tỉ lệ biến chứng là $1,1 \%$ với các biến chứng tương đối nhẹ là nhiễm trùng vết mổ và tổn thương dây thần kinh quặt ngược.

Chúng tôi ghi nhận thời gian phẫu thuật nội soi trung bình là68,9 $\pm 21,2$ phút và không thấy có sự khác biệt có ý nghĩa thống kê giữa 3 nhóm bệnh lý. số lượng máu mất trong phẫu thuật nội soi nhiều nhất gặp ở nhóm u trung thất, và không có sự khác biệt giữa ba nhóm. Kết quả này cũng tương tự như tác giả Trương Thanh Thiết [1] nghiên cứu 74 trường hợp NSTT sinh thiết tại bệnh viện Phạm Ngọc Thạch cho thấy thời gian phẫu thuật trung bình là 51,51 phút. Như vậy NSTT sinh có thời gian phẫu thuật tương đối ngắn, điều này sẽ làm giảm các biến chứng do gây mê, đặc biệt ở những bệnh nhân có hội chứng chèn ép TMC trên.

Về kết quả của nội soi trung thất sinh thiết từ đường cổ, chúng tôi ghi nhận kết quả tốt ở nhóm u trung thất là 93,4\% nhóm hạch trung thất có $\mathrm{u}$ phổi là $100 \%$ nhóm hạch trung thất đơn thuần là 93,3\% tỷ lệ thất bại ở nhóm u trung thất là 4,3\% nhóm hạch trung thất là $2,8 \%$, chúng tôi chỉ ghi nhận một trường hợp có biến chứng chảy máu trong phẫu thuật, trường hợp này cần phải mở xương ức để cầm máu và không ghi nhận các 
biến chứng khác như nhiễm trùng vết mổ, tràn khí màng phổi. Tác giả Trương Thanh Thiết [2], ghi nhận trên 74 trường hợp NSTT sinh thiết ghi nhận một trường hợp chảy máu và một trường hợp nhiễm trùng vết mổ. Qua đó cho thấy NSTT sinh thiết qua đường cổ có tỷ lệ an toàn cao và ít biến chứng có thể áp dụng được trên lâm sàng.

Qua nghiên cứu 81 trường hợp, Chúng tôi ghi nhận được độ nhạy của phương pháp là $98,7 \%$, độ đặc hiệu là $100 \%$, giá trị tiên đoán âm là $66,8 \%$. Khi so sánh với các tác giả Lemaire[6] và tác giả $H$. Porte[7] cũng cho thấy độ nhạy và độ đặc hiệu của nội soi trung thiết sinh thiết là $96 \%$ và $100 \%$. từ đó cho thấy nội soi trung thất sinh thiết có giá trị chẩn đoán cao, có độ nhạy và độ đặc hiệu cao. Nội soi trung thất sinh thiết được xem là tiêu chuẩn vàng trong chẩn đoán các bệnh lý vùng trung thất.

\section{KẾT LUẬN:}

NSTT sinh thiết có giá trị chẩn đoán cao, có độ nhạy và độ đặc hiệu trên $95 \%$. Ngoài ra, NSTT sinh thiết có tỷ lệ biến chứng thấp và gần như không có tử vong, an toàn và có thể thực hiện được trên lâm sàng để chẩn đoán các bệnh lý $\mathrm{u}$, hạch vùng trung thất. NSTT sinh thiết trên những bệnh nhân có hội chứng chèn ép TMC trên cũng cho kết quả tốt,an toàn và ít biến chứng.

\section{TÀI LIÊUU THAM KHẢO}

1. Huỳnh Quang Khánh (2015), "Nghiên cứu kết quả điều trị $\mathrm{u}$ trung thất nguyên phát bằng phẫu thuật nội soi lồng ngực", Luận án tiến sĩ y học, Đại học Y Dược TP. Hồ Chí Minh.

2. Trương Thanh Thiết (2013), "Đánh giá kết quả phương pháp nội soi trung thất lấy mẫu chẩn đoán bản chất hạch trung thất", Luận văn Thạc sĩ y học, Đại học Y Dược TP. Hồ Chí Minh.
3. Ad F. Verhagen Olga C.J.Schuurbiers et al (2013), " Mediastinal staging in daily practice: endosonography, followed by cervical mediastinoscopy. Do we really need both?,".Interactive CardioVascula, 17, pp. 823-8.

4. Carlens E. (1959), "Mediastinoscopy: a method for inspection and tissue biopsy in the superior mediastinum". Dis. Chest 36, pp. 343-7.

5. Hammoud Zane T., Anderson Richard C., Meyers Bryan F., Guthrie Tracey J., Roper Charles L., et al. (1999), "The current role of mediastinoscopy in the evaluation of thoracic disease".J Thorac Cardiovasc Surg, 118, pp. 894-899.

6. Lemaire A. et al (2006), "Nine-year single center experience with cervical mediastinoscopy: complications and false negative rate".Ann Thorac Surg, 82 (4), pp. 1185-9.

7. Porte H. et al (1998), "The role of mediastinoscopy in the diagnosis of mediastinal lymphadenopathy".Eur J Cardiothorac Surg, 13 (2), pp. 196- 199.

8. Rizzato G (1999), "The role of thoracic surgery in diagnosing interstitial lung diseases".Curr. Op. Pul. Med, 5, pp. 284-6.

9. Schil.PE Van, Van Hee. RH and Schoofs. EL (1989), "The value of mediastinoscopy in preoperative staging of bronchogenic carcinoma.The Journal of Thoracic and Cardiovascular Surgery".by The American Association for Thoracic Surgery and The Western Thoracic Surgical Association, 97, pp. 240-244.

10. Theodosios Dosios et al (2005), "Cervical Mediastinoscopy and anterior mediastinotomy in superior vena cava obstruction".Chest, 128 (3), pp. 1551-6.

11. W.R Smythe, Bavaria J.E. and Kaiser L.R (1998), "Mediastinoscopic subtotal removal of mediastinal cysts".Chest, 114, pp. 614-7. 